\title{
CORPO E DOENÇA NO TRÂNSITO DE SABERES*
}

\section{Cynthia Sarti}

\section{Enunciação do problema}

O corpo e a doença constituem objetos cujo conhecimento não encontra um modo de acesso único. Fenômenos sociais e culturais - como qualquer fenômeno humano -, o corpo e a doença, assim como a dor e o sofrimento, constituem objetos de pesquisa que atravessam fronteiras disciplinares por envolverem dimensōes da existência humana reivindicadas, cada uma delas, como próprias de áreas específicas do saber, correspondendo à fragmentação disciplinar que marca o campo científico, neste caso, entre as ciências humanas e as biológicas. Em seu estudo, aparece inevitavelmente o problema de como se relacionam esses

* Agradeço a leitura atenta e os comentários de Patricia Birman e Olgaria Matos à primeira versão do texto.

Artigo recebido em janeiro/2010

Aprovado em agosto/2010 distintos campos do conhecimento, cujos olhares transformam o corpo e a doença em objetos radicalmente diferentes, porque construídos a partir de referências epistemológicas distintas, como as que distinguem o campo da biologia - fundado na suposição da objetividade do conhecimento empírico - e o campo simbólico da antropologia. O problema evidencia-se, sobretudo, diante do fato de que esses estudos, mesmo na perspectiva das ciências sociais, se desenvolvem frequentemente em espaços institucionais vinculados à área da saúde, cuja organização segue a lógica dos saberes biológicos.

Num momento de fragilidade da institucionalização das ciências sociais na área da saúde, Carrara ressaltou que a discussão que propunha, à época, sobre a entrada da antropologia social nos domínios da biomedicina, transformando-a em "'objeto' de nossa própria 'ciência”' (1994, p. 37), talvez interessasse apenas àqueles, como o autor, localiza- 
dos em espaços institucionais vinculados à saúde, portanto "híbridos" do ponto de vista da divisão tradicional das disciplinas científicas. Hoje, diante da visível expansão institucional desse campo de estudos, ${ }^{1}$ juntamente com a abertura das ciências sociais para outras áreas (direito, direitos humanos, segurança pública, relaçôes internacionais, comunicação, meio ambiente etc.), parece-me que a discussão sobre os termos da comunicação possível entre distintos campos do conhecimento se apresenta como um problema não apenas de interesse geral das ciências sociais, mas necessário ao seu empreendimento.

Este ensaio propõe-se a discutir o campo de estudos antropológicos sobre o corpo e a doença, recortando-o a partir da exigência, intrínseca a esse campo, de situar-se em relação aos saberes biológicos. Destaca o modo próprio como a antropologia trata as questóes do corpo e da doença, clássicas em seus estudos, mapeando-o a partir da forma pela qual o saber antropológico se relaciona com os saberes biomédicos nesse campo suposto interdisciplinar.

A noção de "interdisciplinaridade" implica um diálogo entre disciplinas, cuja condição de possibilidade está em manter definidas as diferenças disciplinares, delimitando claramente o lugar de onde se fala e as fronteiras que separam e aproximam os saberes, na tensão que lhe é inerente, uma vez que a tentativa de diálogo não consegue prescindir de alguma, quando não muita, tensão na busca da equidade dos postulados de um campo diante do outro. Não se trata, portanto, de pensar a interdisciplinaridade a partir da possibilidade de uma identificação, mas, ao contrário, o encontro possível supõe a separação prévia, implícita no reconhecimento da alteridade. A identificação anula o outro, em lugar de reconhecê-lo. O primeiro movimento em direção ao diálogo é o da separação, para que o passo seguinte leve ao encontro possível, se o for, entre um e outro (Sarti, 2003).

Embora haja um amplo reconhecimento, na área da saúde, da irredutibilidade dos fenômenos humanos à dimensão biológica, quando um antropólogo toma como objeto de reflexão o corpo, a dor, o sofrimento, a saúde e a doença, ele terá um enfrentamento com um campo de conhecimentos no qual os saberes biológicos se constituem socialmente como referência. Campo difícil, marcado por relações de poder instituídas pelo lugar social que tem o saber biomédico em nossa sociedade. Este saber constitui a representação oficial do corpo humano no mundo ocidental contemporâneo, não apenas no âmbito do "campo científico" - campo de lutas, de disputas, tanto em sua mecânica interna, como em sua relação com a sociedade, como nos mostrou Bourdieu (1976) -, mas como referência cultural para toda a sociedade.

Recorrendo à clássica formulação de Althusser (1985), segundo a qual a ideologia tem como marca interpelar o sujeito, em sua subjetividade, a medicina, como aparelho ideológico, interpela-nos permanentemente, onde quer que estejamos. É ela que, onipresente, vem nos dizer não apenas como curar nossas doenças ou aliviar nosso sofrimento, mas, propriamente, como viver. Embora não seja única e isso se dê num campo de tensões e ambiguidades, é a biomedicina que tem o domínio da concepção de vida e de morte na sociedade ocidental contemporânea.

Cumpre esclarecer que a "biomedicina" é entendida, aqui, como o campo de saberes biológicos no qual se baseia a medicina, envolvendo as instituições e as práticas de saúde a ela associadas. ${ }^{2} \mathrm{O}$ uso do termo coincide com as formulaçôes de Canguilhem, para quem a medicina é uma técnica e uma arte, "situada na confluência de várias ciências, mais do que uma ciência propriamente dita" (2006, p. 6). Este autor busca a relação entre as ciências (biológicas) e a técnica, desvendando os mecanismos pelos quais os postulados científicos (da fisiologia, em particular) se constituem em discursos normativos, que impóem um padrão de normalidade, referência única para pensar a doença (e, consequentemente tratá-la), que é vista como uma variação quantitativa - portanto, a ser mensurada - do estado "normal" da saúde. Sua argumentação em favor de uma diferença qualitativa entre saúde e doença - já que o estado patológico corresponde a um "valor negativo" em relação à "vida" - evidencia a historicidade das concepções científicas do que se constitui (e institui) como normal e patológico e, assim, permite relativizar esses conceitos, abrindo caminho para que a experiência clínica e o discurso do doente - e não apenas a 
"ciência" - possam dizer da doença. Assim, do ponto de vista de uma ciência que informe a clínica, segundo Canguilhem:

É muito importante não confundir a doença com o pecado nem com o demônio. Mas só porque o mal não é um ser não se deve concluir que seja um conceito desprovido de sentido, ou que não existam valores negativos, mesmo entre os valores vitais; não se pode concluir que, no fundo, o estado patológico não seja nada mais do que o estado normal (2006, p. 68).

[...] o conhecimento científico, embora invalidando qualidades que fez aparecer como ilusórias, nem por isso as anula. A quantidade é a qualidade negada, mas não a qualidade suprimida (Idem, p. 73).

Para o antropólogo, definir-se dentro deste campo do conhecimento, confrontando saberes, não é algo que lhe é estranho, por responder ao procedimento, intrínseco à disciplina, de questionar os termos em que se dá a relação entre o pesquisador e o pesquisado, o que nos faz sempre perguntar sobre o estatuto de nosso conhecimento em face do nosso objeto de pesquisa.

Como a antropologia constituiu-se como disciplina científica que estuda sociedades diferentes daquela à qual pertencia o antropólogo, o mundo não-ocidental, a discussão das condições e dos termos em que se dá a relação entre o antropólogo e a cultura que ele estuda se torna um problema não só ético e metodológico, como epistemológico. $\mathrm{O}$ saber antropológico constrói-se precisamente dentro dessa problemática. Para validar a si mesma, a antropologia considera não apenas o diálogo entre o estudioso e seus pares, mas os enunciados válidos na antropologia se fundam, ainda, nas condiçôes de possibilidade do diálogo do pesquisador com seu objeto de estudo, tal como foi ressaltado por Rouanet (1990), em um texto em que precisamente discute ética e antropologia.

Quando se trata de estudar o corpo, a saúde e a doença, o objeto de investigação torna-se, direta ou indiretamente, o próprio campo científico que produz a verdade sobre o que é o corpo, a saúde e a doença no mundo ocidental, ou seja, a biomedicina e seus agentes.
Assim, se entre as questôes em torno das quais se debate a antropologia contemporânea está o questionamento sobre o lugar a partir do qual o antropólogo vê, escuta, fala e escreve, problematizando o antropólogo como autor - questão na qual Geertz (1989) é um nome emblemático - ou, ainda, o que Clifford (1983) denomina a "autoridade etnográfica”, esta questão recoloca-se quando a antropologia tem o corpo, a saúde e a doença como objetos, configurando-se de outra maneira.

A noção de autoridade etnográfica supõe que quem detém a autoridade do conhecimento é o antropólogo, diante de um objeto cujo saber é socialmente desautorizado e deslegitimado; autoridade essa que se constituiu como tal, em face do mundo não-ocidental, a partir da emergência da antropologia como parte das Ciências Humanas no final do século XIX e início do século XX, tendo como contexto histórico o colonialismo europeu. O questionamento dessa autoridade, hoje, no contexto do pós-colonialismo, no interior da própria disciplina, deve-se à associação do discurso antropológico com o poder, herança do contexto do mundo europeu que marcou a fundação da disciplina, que define a supremacia do saber ocidental sobre outras formas de conhecimento. Muita controvérsia e imprecisão surgiram, entretanto, disso que é reconhecido como um postulado evidentemente válido para explicar o surgimento da disciplina, mas não para acompanhar seu próprio desenvolvimento crítico.

A questão ética e epistemológica que está posta para o antropólogo, no que se refere ao estatuto do saber antropológico, é a de buscar o lugar possível de reconhecimento e legitimidade para o discurso de seu "objeto" transformado em sujeito, atribuindo-lhe um estatuto de saber, pensando o discurso como estrutura que inscreve não apenas o sentido da palavra enunciada, mas também o das práticas e das relações nas quais se enuncia. Essa questão é particularmente relevante no campo da saúde, pelo não reconhecimento do discurso do doente pelo discurso biomédico. Reconhecer a condição de sujeito do outro e a legitimidade de seu discurso, entretanto, não se confunde com a (ingênua) reivindicação de uma suposta simetria entre os saberes, questão que transcende o lugar do encontro do antropólogo com o nativo, na pesquisa, 
e é problemática precisamente pelos termos em que se deu e se dá historicamente este encontro. A esse respeito, remeto à argumentação de Duarte:

Hoje veicula-se com frequência a denúncia da disposição interpretativa como o indício de um autoritário privilégio do observador sobre a experiência nativa. A posição do projeto antropológico não tem como não ser assimétrica, uma vez que as disposições culturais que o suscitam são diferentes daquelas que inspiram ou inspiraram a vida de todas as demais ordenaçôes simbólicas emergentes no mundo. Reconhecer essa assimetria "situacional" não significa, porém, assumir necessariamente alguma preeminência ontológica ou epistemológica sobre os "nativos" (inclusive os internos a nossas próprias sociedades, populares ou eruditos, subordinados ou dominantes, marginais ou hegemônicos). A ideia de que seja possível, por outro lado, conceder às concepções do outro um lugar de mais verdade - com maior coerência cosmológica ou autenticidade vivencial, por exemplo - acaba por expressar uma sofisticada e rematada arrogância, como se de nós, ainda seus observadores e descritores, dependessem a revelação e chancela de tal dignidade ontológica (2008, p. 22).

O antropólogo da saúde, no que se refere à relação com o grupo pesquisado, enfrenta uma situação singular. Ao contrário do que geralmente ocorre com seus pares, ele tem que se enfrentar com o fato de que o lugar de autoridade, no campo interdisciplinar da saúde, não é o do saber antropológico, mas o das ciências biomédicas. Assim, é a partir de um lugar desautorizado perante seu objeto de estudo que o antropólogo se situa neste campo. A busca de reconhecimento entre os saberes inverte-se. Converte-se em estratégias para fazer valer os pressupostos epistemológicos relativistas da antropologia num campo referido pelo saber empírico, fundado no pressuposto da objetividade do conhecimento, das ciências biológicas, tomado como referência única na validação do conhecimento científico. ${ }^{3}$

Vale recorrer a uma ideia presente em um texto de Lévi-Strauss, "A sociologia francesa", no qual ele ressalta o que chamou de universalismo da sociologia francesa, pela estreita colaboração entre esta e todas as correntes do pensamento que tivessem o homem ou o estudo do homem como objeto. Assim, esta sociologia, diz ele, "nunca se considera uma disciplina isolada, trabalhando dentro de seu próprio domínio, mas, sobretudo, um método ou uma atitude frente aos fenômenos humanos" (1947, p. 515).

Pode-se reter esta ideia, voltando a um texto anterior à polêmica atual sobre o estatuto do saber nativo ante o antropológico; para falar em outros termos, do método antropológico como uma maneira de olhar o mundo, configurando não apenas uma perspectiva, mas também uma atitude perante os . fenômenos humanos. Pretende-se, aqui, argumentar que o estudo antropológico, dentro do campo dos estudos sobre o corpo, da saúde e da doença, exige que seu olhar - a definição de sua perspectiva teórica e metodológica - venha acompanhado, ao mesmo tempo, de uma atitude do antropólogo frente aos saberes biológicos, que permita estabelecer os termos da comunicação possível entre antropologia e biomedicina, atitude necessária diante do lugar "de mais verdade" ocupado pelos saberes biológicos neste campo. Isso significa dizer que há, implícita, uma dimensão política específica a se enfrentar no desenvolvimento dos estudos antropológicos, e das ciências sociais de modo geral, dentro do campo da saúde. Dimensão que se converte em problema epistemológico, na medida em que de seu enfrentamento depende a própria construção do saber antropológico, em seus próprios termos, de forma a fazer valer a análise antropológica como forma de conhecimento, em si, do corpo, da doença e da saúde - e não como um conhecimento subsidiário, de menor valor heurístico.

A partir do problema assim estabelecido, podese definir um eixo de diferenciação para se entender, em linhas gerais, o campo da antropologia do corpo e da doença, recortando-o pela posição em que se colocam diante das ciências biológicas. Sob este prisma, pode-se falar em duas perspectivas, que correspondem a duas vertentes dentro da antropologia que estuda o corpo, a saúde e a doença: a "antropologia médica”, subsumida na lógica do saber biomédico; e a "antropologia da saúde" (ou da doença), 
que opera a partir de uma noção de cultura que se configura como outra referência epistemológica em relação à biomedicina.

\section{A “antropologia médica”}

A denominada "antropologia médica" (ou "etnomedicina”) tem sua matriz principal na antropologia norte-americana, mas também na anglosaxônica, embora esteja presente de forma geral nos estudos sobre saúde e doença em vários países. Para situar essa vertente, pode-se dizer que estão, entre suas principais referências de origem, os trabalhos de Good (1994), Kleinman (1980, 1995), ScheperHughes e Lock (1987), autores que denominam, eles próprios, seu campo de trabalho como sendo a "antropologia médica". ${ }^{4}$

Correndo o risco de simplificação, inevitável quando se classificam trabalhos diversos dentro de uma categoria comum, pode-se dizer que se trata, genericamente, de uma antropologia, de base empírica, que analisa a diversidade em torno das concepções de corpo e de doença, elaborando o que pode ser considerado um rico inventário dessa variação cultural, situando-se por referência ao sistema biomédico oficial e, frequentemente, a seu serviço. Destaca-se seu caráter instrumental em face das necessidades do sistema médico oficial. A antropologia ocupa, nessa perspectiva, o lugar do tradutor das diferentes linguagens culturais em termos inteligíveis para o campo biomédico, e viceversa.As noções de corpo e doença alheias às definiçôes da biomedicina têm, aqui, o estatuto de um "outro". Permanecem no registro do exótico em relação às referências biomédicas. Estas continuam constituindo-se como lugar absoluto, por sua naturalização, numa perspectiva que, mantendo-se num plano empírico, reduz e encapsula a cultura como fenômeno particular. Assim, essa antropologia, ainda que busque situar-se em relação, caminha paralela ao conhecimento biomédico, andando atrás, pode-se dizer, uma vez que a noção de cultura, essencializada, não marca efetivamente uma alternativa teórica às análises empiricistas sobre corpo, saúde e doença que abra a possibilidade de um encontro de perspectivas diversas. Há, implícitas, imagens reificadas do outro, como nas narrativas coloniais.

A própria nomenclatura, na qual o termo "médica" aparece como adjetivo, ao lado de "antropologia”, substantivo, é sintomática de uma relação em que um dos campos está subsumido ao outro. Essa perspectiva, no Brasil, é mais difundida nos espaços institucionais da saúde e nas publicações desta área, pelas óbvias implicaçôes práticas e políticas que tem o enfrentamento dessa assimetria. ${ }^{5}$

É comum que, nas instituições de saúde, o antropólogo se ocupe das "outras" formas culturais de pensar o corpo, a saúde e a doença, como se isto, por si só, garantisse uma contribuição antropológica à área da saúde. Como se a antropologia se definisse pelo seu objeto e não pelo problema que a constitui como campo disciplinar e como método de investigação, que é a análise dos fenômenos humanos - quaisquer fenômenos humanos - como construção cultural, o que implica que o lugar da alteridade não pode se fixar, porque é sempre uma questão de perspectiva. Desse risco LéviStrauss (1962) nos alertou, já no começo dos anos de 1960, no famoso texto sobre a suposta crise da antropologia em face do desaparecimento das sociedades ditas "primitivas".

Perpassa pelo desencontro entre antropologia e biomedicina uma dificuldade - base do etnocentrismo - que diz respeito ao fato de que a biomedicina, ocidental e contemporânea, é a referência internalizada (inconsciente, portanto) para os cuidados de nossas próprias dores e sofrimentos. Nessa linha, Clavreul (1978) chama a atenção, em sua análise da "ordem médica", para a dificuldade de crítica a esta ordem, uma vez que, como sujeitos culturais, segundo o autor, "cada um de nós é solidário demais com o discurso médico a ponto de não abraçar de antemão suas razões" ${ }^{6}$

$\mathrm{O}$ não enfrentamento desse etnocentrismo, que é, como cultura, da ordem do inconsciente, traduz-se em uma busca ingênua de complementaridade, sem levar em conta que o que diferencia a antropologia e a biomedicina não é o objeto, mas o olhar sobre o objeto. Assim, a antropologia médica incorpora-se à biomedicina e torna-se o que Le Breton (2001) chamou de "antropologia residual", por meio da tentativa conciliatória de dividir objetos 
entre uma e outra, eludindo a tensão que alimenta a busca de reconhecimento dos distintos saberes. Quando não se privilegiam as "outras" culturas, numa redutora divisão de atribuições disciplinares, divide-se o que diz respeito à cultura ocidental, pela qual se referencia a biomedicina, dentro da mesma perspectiva simplificadora. Desta vez, o "social" é considerado atribuição da antropologia (e da sociologia), enquanto o "individual" cabe aos saberes biológicos ou psicológicos.

O fundamento dessa divisão é a identificação, que percorre esse campo, entre o social e os fenômenos "coletivos" como o objeto próprio das ciências sociais, enquanto a biomedicina e a psicologia, ou a psiquiatria, teriam como objeto o "indivíduo", como se o este não fosse, tanto quanto a coletividade, uma categoria social. Reifica-se o social como coletivo, transformando-o em "coisa", atomizada num corpo coletivo, como um organismo, seguindo fielmente o positivismo do Durkheim de As regras do método sociológico. Ambas as dimensões social e individual - são reificadas e naturalizadas, desconsiderando, de um lado, a dimensão de construção histórica e cultural da categoria indivíduo (Dumont, 1993) e, de outro, a complexidade do social como categoria simbólica.

Assim concebido seu objeto, a antropologia encontraria seu lugar no âmbito da saúde pública, da medicina social ou da saúde coletiva, uma vez que é ali o espaço reservado para se tratar do "social” na área da saúde, fazendo do antropólogo um profissional estranho aos outros âmbitos da saúde. Essa antropologia "médica" confere, assim, à antropologia o lugar do saber sobre o outro - exótico -, deixando a biomedicina fora do alcance da análise cultural.

Augé (1986), há tempos, chamou a atenção para a relativa fraqueza teórica da antropologia médica, que a impede de levar adiante a contribuição da disciplina para o campo da saúde, uma vez que gira em torno de questôes já superadas em sua discussão interna, deixando de pensar nos pontos em que o estudo antropológico da doença pode renovar a problemática antropológica.

Para sintetizar a crítica a essa perspectiva, remeto ao trabalho de Duarte (2004) e, em particular, à sua resenha, publicada na revista Physis a respeito das formulações da antropologia médica norteamericana, sobre as doenças chamadas "nervosas":

Perpassam esses trabalhos não só a concepção difusa e mais grosseira de que os sujeitos civilizados são os que operam com noções claras, distintas, racionais, do que é o corpo e do que é espírito ou mente (por oposição aos saberes dos nervos, que confundiriam esses planos classificatórios), mas também a ideia de que as categorias psicologizantes contemporâneas expressam a realidade do que se passa com os seres humanos, enquanto sistemas como o do nervoso são - apenas eles - "culturais" ou "simbólicos" (Duarte, 1993, p. 51).

\section{A antropologia da saúde}

A segunda vertente, que pode ser denominada antropologia da saúde (ou antropologia da doença), está vinculada, sobretudo, a uma tradição que remonta a Marcel Mauss e tem na França o palco principal de sua origem e desenvolvimento (Augé, 1986; Augé e Herzlich, 1984; Laplantine, 1991; Le Breton, 2001). Augé (1986) argumenta, em favor desta vertente, que há apenas uma antropologia, que se atribui distintos objetos empíricos (saúde, doença, religiāo, parentesco), sem se dividir em "subdisciplinas" e pergunta se esses diferentes objetos de observação do olhar antropológico, ao término de seu esforço de construção, não constituíram um único objeto de análise.

A questão é pertinente. Trata-se, como propõe Augé, de pensar não apenas na contribuição da antropologia para o campo da saúde, mas em como a antropologia da saúde e da doença pode ajudar a (re)pensar o objeto da antropologia. Está em jogo não apenas o inventário etnográfico das distintas concepções de saúde e doença e suas consequências práticas para o tratamento, que alimenta a "antropologia médica", mas também a questão teórica que permeia esses estudos num campo em que a noção de cultura se enfrenta, de forma radical - envolvendo uma atitude, ou postura política -, com um saber que lhe nega a razão de ser, postulando a primazia da dimensão bio- 
lógica dos fenômenos em pauta, quando não sua exclusividade.

Comparada à perspectiva anterior, a antropologia da saúde, fiel à tradição relativista da disciplina, considera todos os sistemas médicos, bem como todos os discursos sobre o corpo, a saúde e a doença, como categorias culturais, qualquer que seja sua procedência, pelo simples fato de que eles existem e dedica-lhes o mesmo interesse (Laplantine, 1999). Em muitos sentidos, retornam a Marcel Mauss, para quem não existe assunto nobre e assunto indigno para a ciência. A "ciência" torna-se o objeto de estudo etnográfico. Trata-se de não excluir do campo da análise antropológica, de antemão, qualquer objeto e tratá-lo como categoria cultural, o que implica escapar à lógica das hierarquias do mundo social.

Se a antropologia aceita voltar-se apenas para o que está fora da biomedicina, naturalizando-a, ou privilegia aquilo que constitui o "erro", enfim, a derrota, nesse campo tomado como categoria absoluta, termina por reproduzir as divisões constitutivas do universo simbólico ocidental. Entre essas divisões está a que marca este mundo desde, pelo menos, o Renascimento e sustenta as ciências biológicas, portanto a biomedicina, como saber e práticas: a cisão entre a pessoa e o corpo humano, cisão que, na mesma medida que se realiza e concretiza, evidencia as ambiguidades e as tensões morais que sempre a envolveram.

Segundo Le Breton (2001), essa cisão é anterior ao dualismo cartesiano, que separa corpo e espírito. Este a concretiza e consolida, no século XVII, dentro da concepção mecanicista do corpo como um organismo, mas a raiz histórica, a fundação, desta separação está no desenvolvimento da anatomia, com base na prática oficial de dissecação de cadáveres a partir do começo do século XV. Para este autor, com os anatomistas, em particular com Vesalius, cuja obra, De humani corporis fabrica, é de 1543, nasce uma distinção implícita na episteme ocidental entre o homem e seu corpo. Ali está a fonte do dualismo contemporâneo, que visa ao corpo isoladamente, numa espécie de indiferença em relação à pessoa que o habita, que marca tão claramente a biomedicina até os dias de hoje.?

Entre as expressões mais evidentes dessa clivagem, no mundo contemporâneo, está o transplante de órgãos, cujas dificuldades, que transcendem as questões de ordem técnica, revelam os conflitos e as injunções morais de que se reveste esta prática cultural.

Essa foi, assim, uma mutação ontológica decisiva no mundo ocidental, em sua concepção da pessoa, que possibilita e abre o caminho para o desenvolvimento da anatomia e da fisiologia, nas quais se baseia a biomedicina. Segundo Le Breton (2001), é esta dualidade entre corpo e pessoa que caracteriza, então, a concepção de corpo na modernidade e que se prolonga até a contemporaneidade.

Se a concepção de corpo mais comumente reconhecida em nossa cultura (ocidental) é a que deriva do conhecimento anátomo-fisiológico, foi necessária, como condição de possibilidade deste conhecimento, a construção de uma noção da pessoa cindida, separada de seu corpo, que passou a ser concebido apenas em sua dimensão biológica. $\mathrm{O}$ corpo, separado da pessoa, é pensado como um atributo que, hoje, dados os recursos da biotecnologia, pode inclusive ser modificado. Aqui, "o corpo é associado a ter um corpo e não a ser um corpo", como mostra Le Breton (2001) em sua análise do corpo criado pela anatomia, a partir do Renascimento. ${ }^{8}$

É disso que trata, então, a antropologia da saúde: da noção de pessoa, a concepção do humano, o anthropos, construção necessariamente social e histórica, que está pressuposta nas diversas concepções e práticas que envolvem o corpo, a saúde e a doença, em qualquer âmbito da vida social, em qualquer tempo ou espaço. $\mathrm{O}$ objeto da antropologia da saúde, portanto, não se constitui pelo que é o corpo, a saúde e a doença, mas pelo que sujeitos, em cultura, pensam e vivem o que é o corpo, a saúde e a doença. Como antropólogo, o estudioso coloca-se em perspectiva diante de seu objeto. Longe de constituir-se em realidade objetiva, o que é o corpo depende, sempre, da perspectiva - de dentro e de fora, de cima, de baixo - de quem o carrega consigo, de quem o olha, do que se vê...

É compreensível, assim, a influência decisiva de Marcel Mauss neste campo de estudos, sobretudo por suas formulações sobre o caráter social da noção de pessoa, dos sentimentos ou dos usos do corpo, as "técnicas corporais". Não só Mauss, mas a Escola Sociológica Francesa de modo geral 
(Émile Durkheim, Robert Hertz, entre outros) que, ao afirmar como objeto das ciências sociais "fatos humanos" estudados até então pela medicina e pela psicologia, como corpo, sentimentos, morte e doença, foi pioneira em dar ferramentas teóricas que permitissem tornar inteligíveis esses fenômenos como fatos sociais e culturais.

Pode-se pensar no conhecido estudo de Hertz, A preeminência da mão direita, originalmente publicado em 1909, como emblemático de uma perspectiva de relação entre os saberes biológicos e sociais. $\mathrm{O}$ autor considera as formulaçôes de Broca sobre a anatomia humana, segundo as quais há uma conexão entre a preeminência da mão direita e o maior desenvolvimento do homem no hemisfério cerebral esquerdo, que enerva os músculos do lado oposto. Ele cita Broca," que afirma : "somos destros na mão, porque canhotos no cérebro". ${ }^{10}$ Hertz inverte a questão e pergunta: por que não dizer que somos canhotos no cérebro, por que destros na mão?

Hertz pretende mostrar que, embora exista uma base anatômica para esta assimetria, a desteridade não é uma necessidade natural, mas um ideal. Para ele, a diferença em valor e função entre os dois extremos do nosso corpo não pode ser explicada pela anatomia, porque tem características de uma instituição social, portanto sua explicação pertence à sociologia. Conclui, então, que, se não houvesse a assimetria orgânica, "ela teria que ser inventada", porque corresponde a um valor social.

A atualidade desta afirmação de Hertz aparece claramente quando se pensa nas características e nas definiçôes de corpo, ou de partes deste, que nossa sociedade "inventa" como justificativas morais diante, por exemplo, das novas possibilidades propiciadas pela biotecnologia, em particular, em face do envelhecimento, ou outros processos corporais, como a reprodução (assistida), o transplante de órgãos etc.

\section{O corpo}

A experiência propriamente fisiológica do corpo, portanto, para ser compreendida, requer a referência às categorias sociais que lhe dão sentido. $\mathrm{O}$ corpo é constitutivamente simbólico. A existência humana, sim, é corporal. Nascemos, crescemos, adoecemos e morremos num corpo. Como diz Le Breton (2001), existir significa mover-se corporalmente em um determinado espaço e tempo. No entanto, a forma como cada pessoa vive sua realidade corporal e concebe o corpo que habita é tributária da noção de pessoa, própria à coletividade da qual faz parte.

Quando se fala, no discurso biomédico, em dor corporal, a tendência é associá-la a um fenômeno neurofisiológico. Admite-se que existam "componentes" sociais ou psicológicos na vivência da dor. Pensa-se, entretanto, em uma existência corporal prévia e autônoma - que configura a noção de corpo biológico -, à qual se agregam fatores psíquicos e culturais. Ao contrário desta proposição, o corpo, na perspectiva antropológica, não existe fora do registro simbólico, nem lhe antecede. $\mathrm{O}$ mundo social e cultural não atua ou intervém sobre um corpo preexistente, tomado, neste registro, como "natureza". O corpo constitui-se como realidade humana pelo significado a ele atribuído pela coletividade, significado que é tributário, como já foi dito, da noção de pessoa (Sarti, 2001, 2003).

Não há uma existência corporal prévia, ou seja, uma ordem natural que anteceda à intervenção cultural. O corpo faz-se humano porque está constitutivamente inscrito em um sistema simbólico.

A realidade objetiva atribuída ao corpo pelas ciências biológicas, que o predispõe à observação experimental, é, em si, uma construção simbólica, necessária ao desenvolvimento dessas ciências, como foi demonstrado por Canguilhem (2006) em sua crítica às noções biomédicas de normal e patológico, antes mencionada. Tal como as ciências biológicas concebem o corpo humano como realidade física, objetiva, separada do sujeito que o habita, a literatura antropológica, simetricamente, brinda-nos com inúmeros exemplos etnográficos que mostram distintas formas de pensar a estrutura e o funcionamento do corpo e, sobretudo, de delimitar as fronteiras do corpo em relação ao mundo que o cerca, o que recoloca a questão do corpo como limite entre mim e o outro, tal como posta no mundo ocidental.

Os estudos ameríndios são referência fundamental para a antropologia do corpo e da saúde, por 
demonstrarem a descontinuidade entre os mundos humano, animal e vegetal como uma construção cultural, o que tem implicações decisivas para sua concepção e formas de lidar com a existência corporal (Descola, 1996, 2005; Lima, 2002). Esses dados etnográficos são particularmente relevantes para uma antropologia do corpo, por permitirem desconstruir um dos pilares fundamentais que sustentam a noção de corpo no mundo ocidental, que é a dualidade natureza e cultura, associada à suposição, que dela decorre, de que o corpo biológico faz parte da ordem da natureza. São dados que permitem relativizar o conhecimento biomédico, em comparação com outros sistemas simbólicos, de modo a desfigurar o estatuto de verdade adquirido pela biomedicina no que se refere ao conhecimento sobre corpo, saúde e doença.

No âmbito da crítica à ideia do corpo naturalizado da biomedicina, destacam-se, ainda, os estudos de gênero, que problematizam a construção social do corpo do homem e da mulher. Dentro da questão em pauta - os termos da comunicação possível entre antropologia e biomedicina - remeto ao trabalho de Laqueur (2001), cuja pesquisa evidencia que a diferenciação entre os sexos, na história da medicina, é datada: define-se no século XVIII, quando, segundo o autor, se inventaram "os dois sexos para fundar o gênero", base para a criação da ginecologia como especialidade médica dirigida à mulher. Como demonstra, ainda, uma extensa literatura, tratava-se de consolidar um modelo e uma moral de família por meio do controle disciplinar do corpo e da sexualidade da mulher (Rodhen, 2001).

Ainda no âmbito da necessidade de estranhamento em relação às categorias sobre as quais se assenta nosso sistema cultural, além da noção de "natureza", a noção de "indivíduo" é outro dos eixos - críticos - em torno dos quais gira a discussão de uma antropologia do corpo.

Corpo e indivíduo são noções que caminham juntas na cultura ocidental moderna e contemporânea. A noção atomizada do "indivíduo" como representação do "eu", na sociedade ocidental moderna, valeu-se do corpo. Como lembra Le Breton (2001), Durkheim, ao mencionar a necessidade de um "fator de individuação" na constituição do "eu", afirma: "É o corpo que desempenha esse papel” (Durkheim, 1989, p. 331).

A noção de um "eu", socialmente identificado pela categoria "indivíduo", delimitado por sua existência corporal, é uma aparição recente, mesmo na história do mundo ocidental. Categoria social, historicamente constituída entre os anseios modernos de liberdade e autonomia, o indivíduo contrapõese às amarras do mundo tradicional, onde está submerso na coletividade. Assim, segundo Dumont (1993), o indivíduo constitui-se em um valor.

Como sabemos, a partir do trabalho de $\mathrm{Du}$ mont, o triunfo da ideologia individualista, que sustenta esta representação da pessoa, foi historicamente expresso, no século XVIII, pela Revolução Francesa na Declaração dos Direitos do Homem e do Cidadão. Esse processo consolidou a noção moderna de corpo e de pessoa, ancorando sua representação de si e seu lugar no mundo social.

A análise da noção de indivíduo, como categoria social, configurando um valor da modernidade, está particularmente presente nos estudos antropológicos que tomam como objeto a saúde mental, portanto a psiquiatria e os saberes psicológicos em geral. Destaco a definição, elaborada por Russo, dos "três sujeitos da psiquiatria", que marcam a tensão em torno do indivíduo moderno do qual trata esse ramo da medicina: o sujeito biológico, "determinado por sua natureza biológica”; o sujeito cidadão, "tolhido pelas injunçōes vindas da sociedade (pela opressão sociopolítica)"; e o sujeito da singularidade, "singularizado por seus conflitos intrapsiquicos" (1997, p. 1).

Assim, é nas tensões envolvidas na própria ideia moderna de sujeito/pessoa/indivíduo que se pode igualmente localizar a doença, diante de uma cisão entre corpo e pessoa que, embora corresponda à representação dominante da existência corpórea no mundo ocidental, jamais pode eludir as ambiguidades, os conflitos e as incertezas que a constituem.

\section{A doença}

Se a noção de corpo supõe a noção de pessoa, em qualquer sociedade, a concepção de doença é tributária de ambas essas noçôes. Tal como a con- 
cepção de corpo, os sistemas classificatórios das doenças articulam-se ao universo social que o constrói e o exprime. São construções simbólicas.

Entre a enorme variedade de representações da doença, etnograficamente conhecidas, envolvendo diversos modelos etiológicos e terapêuticos, é possível distinguir, segundo Laplantine (1991), duas tendências, não necessariamente excludentes: o modelo ontológico, que corresponde às medicinas centradas na doença, baseadas em modelo fisicalista (está aqui pressuposta a ideia de um "ser" da doença); e o modelo relacional ou dinâmico, que corresponde às medicinas centradas no doente, baseadas em um modelo que considera a dinâmica interna do organismo como um todo, em sua relação com o meio.

Considerando-se essa classificação, dentro da concepção de corpo predominante na sociedade ocidental contemporânea - que separa corpo e pessoa -, o modelo que lhe corresponde é o ontológico. Em um corpo alheio ao sujeito, a doença lhe é estranha, constituindo-se em entidade autônoma, que fala por si mesma. Assim, outra episte$m e$, distinta daquela na qual se funda e se sustenta a medicina ocidental contemporânea (biomedicina), implica igualmente uma outra concepção de pessoa, diversa em relação àquela que cindiu o ser humano entre corpo e pessoa, autonomizando o corpo em corpo biológico, matéria a ser desvendada, pela experimentação.

Canguilhem (2006) e Foucault (1977) estão entre os filósofos que mais radicalmente fizeram a crítica da pretensão de objetividade do positivismo das ciências biológicas. Para além da evidente afinidade entre ambos, ${ }^{11}$ Macherey (1993) chama a atenção para as diferenças - ou, mesmo, oposições - no ponto de vista desses dois autores, relevantes para se pensar os caminhos possíveis de seu diálogo com a antropologia a partir dos problemas que estão em jogo na leitura paralela das duas obras: $O$ normal e o patológico, cuja versão original é de 1943, e $O$ nascimento da clínica, de 1963. Ambas abordam a questão da relação intrínseca da vida com a morte, ou a vinculação do ser vivo ao ser mortal, tal como ele a vivencia a partir da experiência clínica da doença, mas o fazem de formas diferentes. A diferença fundamental entre os dois reside naquilo para o que cada olha.
Canguilhem fez a crítica da objetividade da biologia a partir da experiência concreta do "ser vivo", abrindo, segundo Macherey, uma perspectiva "fenomenológica" do jogo da vida, apreendido em sua dimensão biológica e no qual se origina a normatividade essencial da vida. Canguilhem atribuía ao ser humano um estado paradoxal (Roudinesco, 2007), o de ser permanentemente atingido pela doença, que se inscrevia na normatividade da vida, polarizada entre valores positivos e negativos. Foucault, por outro lado, fala de um nascimento histórico, situado no desenvolvimento do processo social e político, fazendo, então, uma "arqueologia" das normas médicas, vista do lado do médico e, por trás dele, das instituições médicas, e não do doente. Canguilhem voltou sua atenção para o doente que, para Macherey, é o "grande ausente" na obra de Foucault. Para este, a doença está submetida ao "olhar médico", um olhar normatizado e normatizador. Aqui, Foucault reproduz a análise do olhar vigilante, controlador, absoluto, que persegue sua obra, tendo sua expressão mais clara em Vigiar e punir. ${ }^{12}$

Assim, ainda segundo Macherey (1993), o conceito de experiência aparece em ambos, mas com significados diferentes. Não se trata, para Foucault, de uma experiência do ser vivo, mas uma experiência histórica, anônima e coletiva, de onde surge a figura inteiramente desindividualizada da clínica. A experiência clínica é construída como norma, que se dá numa estrutura triangular: de um lado, está o doente - objeto olhado, objeto do olhar -, de outro, o médico - membro de um "corpo", o "corpo médico", reconhecido como aquele que tem a competência para fazer-se sujeito desse olhar: o "olhar médico". A terceira posição é a da instituição, que legitima socialmente a relação entre o objeto do olhar e o sujeito que olha.

Para realizar essa forma histórica, a priori, que se antecipa à vivência concreta da doença, negligencia-se não apenas o doente, mas também o próprio médico. É essa a estruturação histórica que estabelece a relação entre o ser vivo e o ser mortal. O cadáver aberto e exteriorizado pela dissecação revela a verdade interior da doença, evidencia a relação do médico com o doente: não há sujeitos que sofrem, há estruturas que levam ao sofrimento. Nas condições em que se realiza a experiência clínica, a mor- 
te, e também a vida, deixam de ser um "absoluto ontológico e existencial” e, ao mesmo tempo, adquirem uma dimensão epistemológica: "por paradoxal que isso possa parecer, ela [a morte] 'ilumina' a vida" (Macherey, 1993, p. 291).

Para Canguilhem (2006), a experiência fundamental no conhecimento sobre a doença é a do doente. $\mathrm{O}$ conceito central para sua análise é a de "ser vivo", sujeito de uma experiência que o expõe, de maneira intermitente e permanente, à possibilidade do sofrimento (Macherey, 1993). A doença, parte da vida, é um modo de estar na vida. Ela exprime um outro modo de viver. Institui, portanto, uma diferença: "Não existe fato que seja normal ou patológico $\mathrm{em}$ si. A anomalia e a mutação não são, em si mesmas, patológicas. Elas exprimem outras formas de vida possíveis" (Idem, p. 113).

E, assim, a ideia de cura remete a algo inexistente anteriormente à experiência da doença, um novo estado fisiológico: "nenhuma cura é uma volta à inocência biológica. Curar é criar para si novas formas de vida, às vezes superiores às antigas. Há uma irreversibilidade da normatividade biológica" (Idem, p. 176).

Pode-se ver uma afinidade entre o pensamento de Canguilhem e pensamento antropológico pelo lugar central assumido pelo problema da diferença em ambos. Em Canguilhem, a problemática da diferença surge de seu olhar sobre a experiência concreta do "ser vivo" - que adoece - para pensar sobre a doença, que leva a dar ao doente um lugar fundamental no conhecimento da doença, indissociando-os, perspectiva que inverte os termos do conhecimento e abre o caminho para a crítica do etnocentrismo da biomedicina: não é a ciência que informa a clínica, mas o inverso.

Zempléni (1994), ao dizer "que o objeto da etnomedicina ou da antropologia médica, continua sendo a doença e não o doente", remete às possibilidades analíticas abertas pela língua inglesa que distingue entre disease e illness, ressaltada pela antropologia anglosaxônica, e lembra que essa distinção recupera a que René Lériche, médico francês, estabeleceu, em 1936, de forma pioneira no campo biomédico, entre a "doença do médico" e a "doença do doente” (Lériche, 1936). Não sem razão, é por meio do estudo da dor, cujo conhecimento não pode prescindir da experiência do doente, que Lériche chegou à relevância do lugar do doente no saber sobre a doença. Dessa forma, é a Lériche que Canguilhem presta tributo em seu estudo sobre o normal e o patológico, em particular quando afirma: "Sempre se admitiu, e atualmente é uma realidade incontestável, que a medicina existe porque há homens que se sentem doentes e não porque existem médicos que os informam de suas doenças" (2006, p. 59).

A tarefa do antropólogo torna-se, assim, a de construir um conhecimento sobre saúde e doença que não seja mero subsidiário da biomedicina, mas ao mesmo tempo possa com ela relacionar-se, posto que, como cientistas sociais, não há como ignorar o discurso no qual se assenta a concepção da sociedade ocidental sobre aquilo que tomamos como objeto de reflexão - base do cuidado de nossas próprias dores, doenças e sofrimentos -, sob o risco de uma excessiva autorreferência, postura defensiva que compromete não apenas o alcance social do empreendimento, mas seu próprio valor heurístico.

\section{Considerações finais}

Para finalizar, gostaria de ressaltar o lugar da antropologia no estudo do corpo, da saúde e da doença a partir do que a constitui como disciplina, no interior do campo das ciências humanas. Pode-se recorrer a Foucault, quando o autor atribui à antropologia (etnologia) - ao lado da psicanálise - um lugar singular nesse campo, uma vez essa disciplina se constitui em um e por um confronto: "a etnologia só assume suas dimensões próprias na soberania histórica [...] do pensamento europeu e da relação que o pode confrontar com todas as outras culturas e com ele próprio" (1992, p. 394).

Ao argumentar que a antropologia, como a psicanálise, interroga "não o próprio homem, tal como pode aparecer nas ciências humanas, mas a região que torna possível, em geral, um saber sobre o homem", Foucault atribui aquilo que a distingue por "alojar-se no interior da relação singular que a razão ocidental estabelece com as outras culturas", não ocidentais, e, a partir daí, traçar "o contorno das representações que os homens, numa civiliza- 
ção, podem dar de si mesmos" (Idem, p. 395). É, assim, na tensão constitutiva desse estar dentro e simultaneamente enfrentar-se com o estar fora da racionalidade ocidental - na qual a biomedicina se fundamenta e se sustenta -, numa relação de alteridade, que a antropologia se move no campo científico que estuda o corpo, a saúde e a doença. Tensão que é tributária do fato de que, se a antropologia nasceu sob a égide do pensamento universalista ocidental, é ela a crítica do etnocentrismo e do racionalismo implícitos neste pensamento.

No enfrentamento do caráter fundante e inelutável dessa tensão - um movimento permanente entre o dentro e o fora -, está a possibilidade de a antropologia dar sua contribuição efetiva aos estudos do corpo e da doença, constituindo-se em referência alternativa à racionalidade biomédica, mas desde que se mantenha em constante vigilância. A força avassaladora do discurso biomédico sobre as concepções e as práticas que envolvem o corpo, a saúde e a doença em nossa sociedade não pode eludir a responsabilidade do antropólogo da saúde diante do fato de que ele faz, acima de tudo, antropologia e se pauta por suas referências epistemológicas e pelos debates que a animam, o que o situa, dentro do campo da saúde, por definição, num lugar de resistência.

\section{Notas}

1 No caso da antropologia, essa expansão reflete-se em sua significativa presença nos debates em congressos da área (Reunião Anual da Anpocs, Reunião Brasileira de Antropologia e Reunião de Antropologia do Mercosul, entre outros).

2 Para a discussão da biomedicina (ou racionalidade biomédica), como a referência cultural que informa as concepções e as práticas de saúde e a noção de doença no mundo ocidental contemporâneo, ver Camargo Jr. (1997, 2003).

3 O que pode ser observado, por exemplo, na definição de critérios de avaliação da produção científica dos pesquisadores, na pesquisa e na pós-graduação da área da saúde, que obedecem estritamente à lógica das ciências biológicas, desconsiderando a natureza distinta da produção do conhecimento nas ciências humanas. Sejam cientistas das áreas biológicas ou hu- manas, de todos é exigida a publicação nas revistas científicas avaliadas segundo critérios biomédicos, sem qualquer abertura para o reconhecimento da diferença, o que coloca os pesquisadores da área de ciências humanas numa posição estrutural de desvantagem relativa, com os problemas que daí decorrem no que diz respeito, sobretudo, ao acesso a recursos para pesquisa.

4 No entanto, apesar de esses autores se (auto)situarem no campo da antropologia médica, muito do que caracterizou essa vertente, tal como aqui descrito, não necessariamente se aplica in totum ao trabalho isolado desses autores, em particular as importantes contribuições de Arthur Kleinman e Margareth Lock. Uma análise mais detalhada dessa tendência implicaria considerar os contextos sociais e institucionais específicos de constituição do campo, além do perfil de seus pesquisadores, o que não é o escopo deste ensaio, mais panorâmico.

5 No que se refere às publicações, as revistas que veiculam artigos da área de antropologia na perspectiva da “antropologia médica” se encontram prioritariamente entre aquelas da área da saúde, em particular da saúde pública.

6 No original: "Chacun de nous est trop solidaire du discours médical pour ne pas en épouser d'avance les raisons" (p. 27).

7 Se a dissecação de cadáveres cinde o humano no século XVII, no século XIX vem redefinir a relação com a morte. É interessante mencionar, aqui, "as mais belas páginas”, segundo Roudinesco (2007), do livro de Foucault (1977), Abram alguns cadáveres, no qual ele fala de Bichat - cirurgião que, no começo do século XIX, inventou, com seus estudos de anatomia patológica - nos quais abria cadáveres -, uma nova relação entre vida, doença e morte. A morte deixa de ser um absoluto, é retirada do domínio da religião pela ciência. A passagem da vida para a morte passa a ser vista a partir de processos fisiológicos e patológicos inscritos nos próprios organismos vivos. "Em lugar de permanecer o que tinha sido durante tanto tempo, noite em que a vida se apaga e em que a própria doença se confunde, ela [a morte] é dotada, de agora em diante, do grande poder de iluminação que domina e desvela tanto o espaço do organismo quanto o tempo da doença” (Foucault, 1977. p. 165).

8 No original: "Le corps est associé à l'avoir et non plus à l'être" (p. 47)

9 Paul Broca, cirurgião e antropólogo francês (1824-1880), estudioso do cérebro e das funções da linguagem. 
10 No original: "nous sommes droitiers de la main, parce que nous sommes gauchers du cerveau" (p. 81).

11 Afinidade à qual se refere Roudinesco (2007, p. 44), em seu trabalho sobre os filósofos franceses da segunda metade do século XX. Canguilhem foi o orientador da tese de doutorado em filosofia de Foucault (Loucura e desrazão: história da loucura na idade clássica).

12 É interessante observar o comentário de Richard Sennett em Carne e pedra: o corpo e a cidade na civilização ocidental (1997), numa parte da introdução ao livro que denominou "Uma nota pessoal", na qual fala da influência de seu amigo Foucault nessa obra, que foi iniciada junto com ele, mas mudou de direção, depois de sua morte. Afirma o autor: "Numa de suas obras mais conhecidas - Vigiar e punir - Foucault imaginou o corpo humano asfixiado pelo nó do poder. À medida que seu próprio corpo enfraquecia, ele procurou desfazer esse nó; no terceiro volume da sua História da sexualidade, e ainda mais em notas elaboradas para os tomos que não viveu para completar, Michel Foucault explorou os prazeres corporais que não se deixam aprisionar pela sociedade. Sua paranoia sobre controles, tão marcante em toda sua vida, abandonou-o quando começou a morrer" (p. 25).

\section{BIBLIOGRAFIA}

ALTHUSSER, Louis. (1985), "Aparelhos ideológicos de Estado: notas sobre os aparelhos ideológicos do Estado". Trad. Walter José Evangelista e Maria Laura Viveiros de Castro. 2 ed. Rio de Janeiro, Graal.

AUGÉ, Marc. (1986), "L'anthropologie de la maladie”. L'Homme, XXVI (97-98): 81-90.

AUGÉ, Marc \& HERZLICH, Claudine. (1984), Le sens du mal: anthropologie, histoire, sociologie sociologie de la maladie. Paris, Éditions des Archives Contemporaines.

BOURDIEU, Pierre. (1976), "Le champ scientifique". Actes de la Recherche en Sciences Sociales, 2/3: 88-104.

CAMARGO JR., Kenneth Rochel de. (1997), “A biomedicina”. Physis: Revista de Saúde Coletiva, 7 (1): 45-68.

. (2003), Biomedicina, saber e ciência: uma abordagem crítica. São Paulo, Hucitec.

CANGUILHEM, Georges. ([1966] 2006), O nor- mal e o patológico. Trad. Maria Thereza Redig de Carvalho Barrocas. 6 ed. revista. Rio de Janeiro, Forense Universitária.

CARRARA, Sergio. (1994), "Entre cientistas e bruxos: ensaio sobre os dilemas e perspectivas da análise antropológica da doença”, in P. C. Alves e M. C. S. Minayo (orgs.), Saúde e doença: um olhar antropológico. Rio de Janeiro, Editora Fiocruz, pp. 33-45.

CLAVREUL, J. (1978), L'ordre médical. Paris, Édition du Seuil.

CLIFFORD, James. (1983), "On ethnographic authority”. Representations, (2): 132-143.

DESCOLA, Philippe. (1996), "Constructing natures: symbolic ecology and social practices", in P. Descola e G. Pálsson (orgs.), Nature and society: anthropological perspectives. Londres, Routledge, pp. 82-102.

(2005), Par-delà nature et culture. Pa-

ris, Gallimard.

DUARTE, Luiz Fernando Dias. (1993), “Os nervos e a antropologia médica norte-americana: uma revisão crítica”. Physis: Revista de Saúde Coletiva, 3 (2): 43-73.

. (2004), "A pulsão romântica e as ciências humanas no ocidente". Revista Brasileira de Ciências Sociais, 19 (55): 5-18.

DUARTE, Luiz Fernando Dias \& GOMES, Edlaine de Campos. (2008), Três familias: identidades e trajetórias transgeracionais nas classes populares. Rio de Janeiro, Editora FGV.

DUMONT, Louis. (1993), O individualismo: uma perspectiva antropológica da ideologia moderna. Trad. Álvaro Cabral. Rio de Janeiro, Rocco.

DURKHEIM, Émile. ([1895] 1973) As regras do método sociológico. Trad. Margarida Garrido Esteves, in Comte/Durkheim. São Paulo, Abril Cultural (col. Os Pensadores, 33), pp. 373-463. . ([1912] 1989), As formas elementares da vida religiosa: o sistema totêmico na Australia. Trad. Joaquim Pereira Neto. São Paulo, Paulinas.

FOUCAULT, Michel. (1977), O nascimento da clínica. 1 ed. brasileira. Trad. Roberto Machado. Rio de Janeiro, Forense Universitária.

. ([1966] 1992), As palavras e as coisas: uma arqueologia das ciências humanas. Trad. 
Salma Tannus Muchail. 6 ed. brasileira. São Paulo, Martins Fontes.

GEERTZ, Clifford. (1989), El antropólogo como autor. Trad. Alberto Cardín. Barcelona/Buenos Aires/México, Paidós.

GOOD, Byron J. (1994), Medicine, rationality and experience. Cambridge, University of Cambridge Press.

HERTZ, Robert. ([1909] 1970), "La préeminence de la main droite: étude sur la polarité religieuse", in R. Hertz, Sociologie religieuse et folklore. 2 ed. Paris, PUF, pp. 80-101. Disponível em $<$ http://classiques.uqac.ca/classiques/hertz_robert/socio_religieuse_folklore/hertz_socio_rel_ folklore.pdf>, acesso em 7/1/2010.

KLEINMAN, Arthur. (1980), Patients and healers in the context of culture: an exploration of the borderland between anthropology, medicine and psychiatry. Berkeley/Los Angeles, University of California Press.

. (1995), Writing at the margin: discourse between anthropology and medicine. Berkeley/ Los Angeles, University of California Press.

LAPLANTINE, François. (1991), Antropologia da doença. Trad. Walter L. Siqueira. 1 ed. brasileira. São Paulo, Martins Fontes.

LAQUEUR, Thomas. (2001), Inventando o sexo: corpo e gênero dos gregos a Freud. Trad. Vera Whately. Rio de Janeiro, Relume Dumará.

LE BRETON, David. (2001), Antropologie du corps et modernité. 2 ed. Paris, PUF.

LÉRICHE, René. (1936), "Introduction générale; de la santé à la maladie; la douleur dans les maladies; où va la medicine?". Encyclopédie française, t. VI.

LÉVI-STRAUSS, Claude. (1947), "La sociologie française", in G. Gurvitch e W. Moore (ed.). La sociologie au XXe siècle. Paris, PUF, pp. 513545.

(1962), "A crise moderna da antropologia”. Trad. Ruth C. L. Cardoso. Revista de Antropologia, 10 (1 e 2): 17-26.

LIMA, Tânia Stolze. (2002), "O que é um corpo?”. Religião e Sociedade, 22 (1): 9-20.

MACHEREY, Pierre. (1993), "De Canguilhem à Canguilhem en passant par Foucault". Actes $d u$ Colloque. Paris, Bibliothèque du Collège In- ternational de Philosophie/Albin Michel, pp. 286-294.

MAUSS, Marcel. ([1923-1924] 1974a), "Efeito físico no indivíduo da idéia de morte sugerida pela coletividade", in Sociologia e antropologia. Trad. Lamberto Puccinelli. São Paulo, Epu/Edusp, vol. 2, pp. 185-208. ([1923-1924] 1974b), "As técnicas corporais", in , Sociologia e antropologia. Trad. Lamberto Puccinelli. São Paulo, Epu/Edusp, vol. 2, pp. 209-233. . ([1921] 1979) "A expressão obrigatória dos sentimentos”, in Mauss. São Paulo, Ática (col. Grandes Cientistas Sociais, 11), pp. 147-153.

ROHDEN, Fabíola. (2001), Uma ciência da diferença: sexo e gênero na medicina da mulher. Rio de Janeiro, Editora Fiocruz.

ROUANET, Sergio Paulo. (1990), "Ética e antropologia”. Estudos avançados, 4 (10): 111-150.

ROUDINESCO, Elizabeth. (2007), Filósofos na tormenta: Canguilhem, Sartre, Foucault, Althusser, Deleuze e Derrida. Trad. André Telles. Rio de Janeiro, Jorge Zahar Editor.

RUSSO, Jane A. (1997), "Os três sujeitos da psiquiatria”. Cadernos do Ipub, 8: 12-23.

SARTI, Cynthia A. (2001), "A dor, o indivíduo e a cultura". Saúde e Sociedade, 10 (1): 3-13. . (2003), O reconhecimento do outro: uma busca de diálogo entre Ciências Humanas e Ciências da Saúde. São Paulo, tese de livre docência, Universidade Federal de São Paulo/ Escola Paulista de Medicina.

SENNETT, Richard. (1997), Carne e pedra: o corpo e a cidade na civilização ocidental. Rio de Janeiro, Record.

SCHEPER-HUGHES, Nancy \& LOCK, Margareth. (1987), "The mindful body: a prolegomenon to future work in Medical Anthropology." Medical Anthropology Quarterly, 1 (1): 6-41.

VELHO, Gilberto. (1981), "Relações entre a antropologia e a psiquiatria”, in Individualismo e cultura: notas para uma antropologia da sociedade contemporânea. Rio de Janeiro, Zahar, pp. 93-102.

ZEMPLÉNI, Andras. (1994), A “doença” e suas “causas”. Cadernos de Campo, 4: 137-163. 


\section{CORPO E DOENÇA NO} TRÂNSITO DE SABERES

Cynthia Sarti

Palavras-chave: Corpo; Saúde e doença; Antropologia da saúde; Biomedicina.

Este ensaio discute os estudos antropológicos sobre corpo e doença, a partir da forma como se relacionam com os saberes biológicos no campo científico da Saúde. A pesquisa antropológica implica uma atitude ante esses saberes de tal ordem que a forma como ela se situa em relação a eles se converte em problema epistemológico, definindo o estatuto do saber antropológico nesse campo marcado pela hegemonia das ciências biomédicas. Sob esse prisma, diferenciam-se duas vertentes: a antropologia médica, subsumida na lógica do saber biomédico, e a antropologia da saúde, cuja forma de operar a noção de cultura configura outra referência epistemológica, apontando para a efetiva contribuição da antropologia para esse campo, que supóe, em si, o distanciamento das referências de sentido que sustentam a biomedicina.

\section{BODY AND ILLNESS IN THE TRANSIT OF KNOWLEDGES}

\section{Cynthia Sarti}

Keywords: Body; Health and illness; Anthropology of health; Biomedicine.

This essay discusses the anthropological studies on body and illness from the way they relate to biological knowledges in the scientific field of Health. Anthropological research implies an attitude towards these knowledges of such an order that the way it places itself before them turns to be an epistemological problem, defining the status of the anthropological knowledge in this field marked by the hegemony of the biological sciences. From this point of view, two trends are distinguished: Medical Anthropology, imbedded in the logic of biomedical knowledge, and Anthropology of Health, whose way of using the notion of culture aims at another epistemological reference, pointing out the effective anthropological contribution to this field, which supposes, in itself, being apart from the significant references that support the bio-medicine.

\section{CORPS ET MALADIE AU TRANSIT} DES SAVOIRS

\section{Cynthia Sarti}

Mots-clés: Corps; Santé et maladie; Anthropologie de la santé; Biomédecine.

Cet essai discute les études anthropologiques sur le corps et la maladie à partir de la façon dont elles se lient aux savoirs biologiques dans le domaine scientifique de la Santé. La recherche anthropologique implique une attitude telle face à ces savoirs que la façon dont elle se situe par rapport à eux se convertit en un problème épistémologique, qui définit le statut du savoir anthropologique dans ce domaine marqué par l'hégémonie des sciences biomédicales. Sous ce point de vue, deux courants s'opposent : l'anthropologie médicale, qui s'insère dans la logique du savoir biomédical, et l'anthropologie de la santé, dont la façon d'opérer la notion de culture configure une autre référence épistémologique, qui indique vers la contribution effective de l'anthropologie à ce domaine qui suppose, en soi, l'éloignement des références de sens qui soutiennent la biomédecine. 